BNL-113713-2017-JA

\title{
In Situ Probes of Capture and Decomposition of Chemical Warfare Agent Simulants by Zr-based Metal Organic Frameworks
}

Anna M. Plonka, Qi Wang, Wesley O. Gordon, Alex Balboa, Diego Troya, Weiwei Guo, Conor H. Sharp, Sanjaya D. Senanayake, John R. Morris, Craig L. Hill, Anatoly I. Frenkel1

Submitted to Journal of the American Chemical Society

December 2016

Chemistry Department

Brookhaven National Laboratory

\author{
U.S. Department of Energy \\ USDOE Office of Science (SC), \\ Basic Energy Sciences (BES) (SC-22)
}




\section{DISCLAIMER}

This report was prepared as an account of work sponsored by an agency of the United States Government. Neither the United States Government nor any agency thereof, nor any of their employees, nor any of their contractors, subcontractors, or their employees, makes any warranty, express or implied, or assumes any legal liability or responsibility for the accuracy, completeness, or any third party's use or the results of such use of any information, apparatus, product, or process disclosed, or represents that its use would not infringe privately owned rights. Reference herein to any specific commercial product, process, or service by trade name, trademark, manufacturer, or otherwise, does not necessarily constitute or imply its endorsement, recommendation, or favoring by the United States Government or any agency thereof or its contractors or subcontractors. The views and opinions of authors expressed herein do not necessarily state or reflect those of the United States Government or any agency thereof. 


\title{
In Situ Probes of Capture and Decomposition of Chemical Warfare Agent Simulants by Zr-based Metal Organic Frameworks
}

\author{
Anna M. Plonka, ${ }^{1}$ Qi Wang, ${ }^{1}$ Wesley O. Gordon, ${ }^{2}$ Alex Balboa, ${ }^{2}$ Diego Troya, ${ }^{3}$ Weiwei Guo, ${ }^{4}$ Conor H. \\ Sharp, ${ }^{3}$ Sanjaya D. Senanayake, ${ }^{5}$ John R. Morris, ${ }^{3}$ Craig L. Hill, ${ }^{4}$ Anatoly I. Frenkel ${ }^{1, *}$ \\ ${ }^{1}$ Department of Material Science and Chemical Engineering, Stony Brook University, Stony Brook, NY 11794, USA \\ ${ }^{2}$ U.S. Army Edgewood Chemical Biological Center APG, MD 21010, USA \\ ${ }^{3}$ Department of Chemistry, Virginia Tech, Blacksburg, VA 24061, USA \\ ${ }^{4}$ Department of Chemistry, Emory University, Atlanta, GA 30322, USA \\ ${ }^{5}$ Department of Chemistry, Brookhaven National Laboratory, Upton, NY 11973, USA
}

\begin{abstract}
Zr-based metal organic frameworks (MOFs) have been recently shown to be among the fastest catalysts of nerveagent hydrolysis in solution. We report a detailed study of the adsorption and decomposition of a nerve-agent simulant, dimethyl methylphosphonate (DMMP), on UiO-66, UiO-67, MOF-808 and NU-1000 using synchrotron-based X-ray powder diffraction, Xray absorption, and infrared spectroscopy, which reveals key aspects of the reaction mechanism. The diffraction measurements indicate that all four MOFs adsorb DMMP (introduced at atmospheric pressures through a flow of helium or air) within the pore space. In addition, the combination of X-ray absorption and infrared spectra suggests direct coordination of $\mathrm{DMMP}^{\mathrm{N}}$ to the $\mathrm{Zr}_{6}$ cores of all MOFs, which ultimately leads to decomposition to phosphonate products. These experimental probes into the mechanism of adsorption and decomposition of chemical warfare agent simulants on Zr-based MOFs open new opportunities in rational design of new and superior decontamination materials.
\end{abstract}

Chemical warfare agents continue to present a significant threat in the event of war or terrorist attacks. ${ }^{1}$ Current defense technology for filtration and decomposition of CWAs mainly consists of activated carbons in pure or impregnated form. However, significant drawbacks of those filters, such as secondary emission after saturation, low capacity for longterm activation, and ultimate disposal, present an urgent need to develop improved materials capable of fast adsorption and decontamination of CWAs under ambient conditions. ${ }^{2}$ These challenges have motivated research into a new generation of sorptive or catalytically active materials for CWA decontamination, including metal oxides, polyoxometalates, ${ }^{5,6}$ and metal organic frameworks. ${ }^{7-10}$

Metal organic frameworks are a novel class of materials, formed by inorganic cores connected by organic linkers to form extended networks with high porosity and ultrahigh surface areas. ${ }^{11}$ MOFs can therefore provide adsorption properties competitive with commercially available adsorbents, ${ }^{12,13}$ and have found application in gas storage, ${ }^{13,14}$ gas separation, ${ }^{15,16}$ and catalysis, including catalytic decontamination of toxic chemicals. ${ }^{17-20} \mathrm{Zr}$-based MOFs are particularly interesting for catalysis due to their stability in water and at high temperatures. ${ }^{21-23}$ Indeed, some Zr-MOFs have been recently proven to decompose CWAs and CWA simulants. $^{7-10}$ While these studies have reported turnover frequencies and CWA half lives on Zr-MOFs, no experimental probes into the atomistic reaction mechanism are available to date.

This Communication provides insight into the atomic-scale mechanism for CWA adsorption and decomposition on four Zr-based MOFs that decompose CWAs and CWA simulants. ${ }^{9,10,24,25}$ Specifically, we studied the adsorption of the nerve-agent Sarin simulant DMMP (dimethyl methylphosphonate), on $\mathrm{UiO}-66\left[\mathrm{Zr}_{6}\left(\mu_{3}-\mathrm{O}\right)_{4}\left(\mu_{3}-\mathrm{OH}\right)_{4}(\mathrm{bdc})_{6}\right.$; bdc: benzene-1,4-dicarboxylate $]$ UiO-67 $\left[\mathrm{Zr}_{6}\left(\mu_{3}-\mathrm{O}\right)_{4}\left(\mu_{3^{-}}\right.\right.$ $\mathrm{OH})_{4}(\mathrm{bpdc})_{6}$; bpdc: biphenyl-4,4'-dicarboxylate], MOF-808 $\left[\mathrm{Zr}_{6}\left(\mu_{3}-\mathrm{O}\right)_{4}\left(\mu_{3}-\mathrm{OH}\right)_{4}(\mathrm{OH})_{6}\left(\mathrm{H}_{2} \mathrm{O}\right)_{6}(\mathrm{btc})_{2} ; \quad\right.$ btc: benzene-1,3,5tricarboxylate $]$ and $\mathrm{NU}-1000 \quad\left[\mathrm{Zr}_{6}\left(\mu_{3}-\mathrm{O}\right)_{4}\left(\mu_{3^{-}}\right.\right.$ $\mathrm{OH})_{4}(\mathrm{OH})_{4}\left(\mathrm{H}_{2} \mathrm{O}\right)_{4}(\text { tbapy })_{2}$; tbapy: tetratopic 1,3,6,8-tetrakis(pbenzoate) pyrene] using in situ, synchrotron powder X-ray diffraction (PXRD) and extended X-ray absorption spectroscopy (EXAFS). PXRD and EXAFS illuminate both the macroscopic crystalline and atomic length scales, affording deep understanding of the DMMP-MOF interaction. ${ }^{26,27}$ The combination of these two in situ methods is essential for developing an overall understanding of MOF chemistry because they bridge localized site-specific reactions with macroscopic changes o the MOF structures.

All four MOFs studied in this work contain cationic $\mathrm{Zr}_{6}$ nodes, connected by aromatic carboxylate ligands to form porous frameworks, but the topology of the frameworks differs between them (Fig. S1). UiO-66 and UiO-67 are 
isostructural; in both materials, the nodes are 12-connected with ditopic ligands, resulting in cubic frameworks. ${ }^{28}$ The structure of NU-1000 is based on 8-connected $\mathrm{Zr}_{6}$ nodes and tetratopic tbapy ligands that form a hexagonal network. NU1000 has significantly larger pores than UiO-66, UiO-67 or
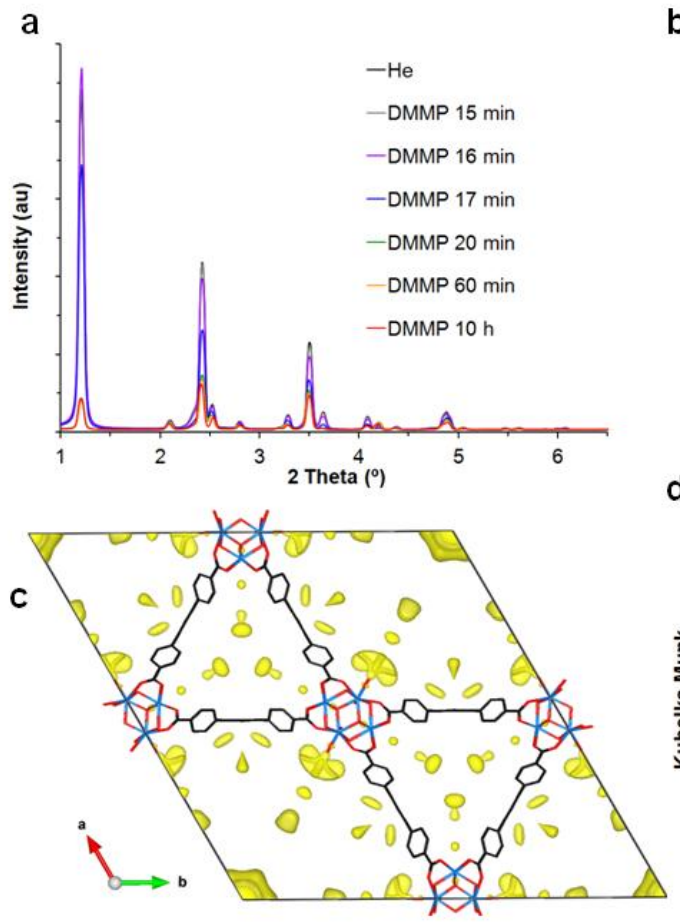

MOF-808 with an aperture size of $31 \AA{ }^{29}$ MOF-808 possesses a cubic framework formed by 6-connected $\mathrm{Zr}_{6}$ nodes and tritopic btc ligands. Because the node is only 6-connected, MOF-808 offers more open $\mathrm{Zr}$ sites, and better spatial accessibility than the 12 - or 8 -connected MOFs. ${ }^{30}$

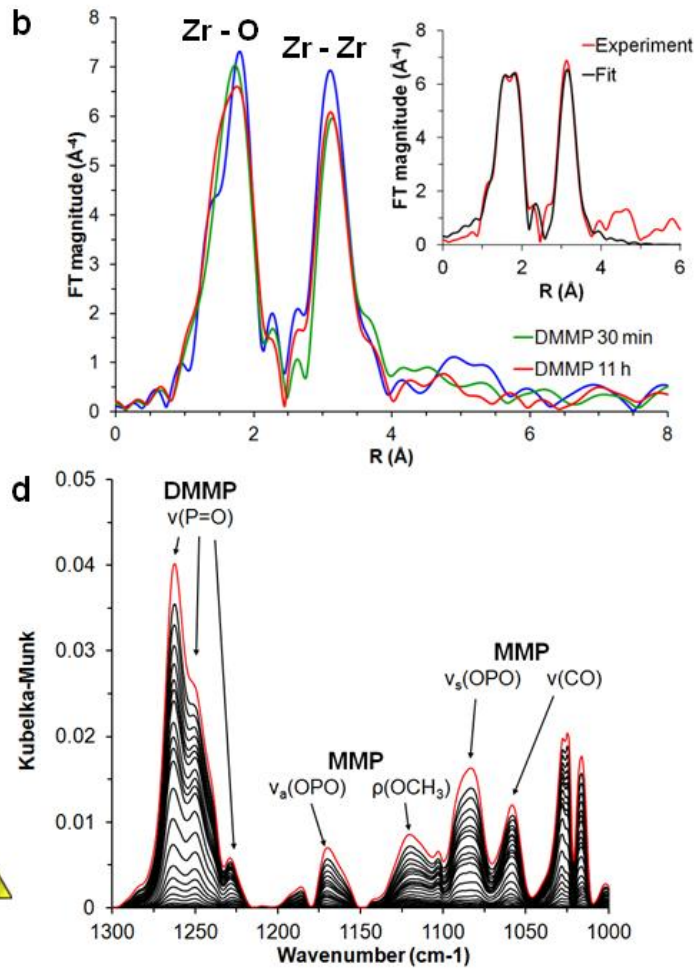

Figure 1. (a) In situ PXRD data of NU-1000 collected during the exposure to DMMP; (b) In situ EXAFS data of NU-1000 collected during the exposure to DMMP. Inset shows experimental and fitted curves for the last DMMP dataset. (c) Difference Fourier electron density map of DMMP-treated NU-1000 after 10 h. Zr shown in blue, C - black and O - red. Hydrogen atoms have been removed for clarity Electron density isosurface drawn at $0.3 \overline{\mathrm{e}} / \AA^{3}$ in yellow; (d) Fingerprint region of time-resolved DRIFTS spectra for DMMP-treated NU-1000. Red line shows the last dataset collected after 213 min.

The stages of DMMP adsorption and reaction on $\mathrm{Zr}-\mathrm{MOF}$ were investigated by performing in situ PXRD experiments, where the desolvated samples were exposed to DMMP vapor for up to $11 \mathrm{~h}$. Examination of the collected patterns clearly reveals that each sample undergoes structural changes during exposure. The most apparent change is the decrease in intensity of the low angle reflection relative to higher angle reflections (Fig. 1a, Fig S2). This behavior is typically indicative of adsorbents entering porous materials, which suggests that DMMP diffused into the pore space of the MOFs during exposure. ${ }^{31}$ A similar, but reverse effect can be observed upon thermal removal of the adsorbents in a $\mathrm{He}$ flow. This thermal desorption process also appears to decompose UiO-66 and UiO-67, as the reflection peaks in Fig. S2 significantly broaden and weaken, indicative of framework collapse. Note that, prior to exposure, the MOFs demonstrated thermal stability up to $150{ }^{\circ} \mathrm{C}$; therefore, DMMP or products of DMMP decomposition form strong interactions with the MOFs or produce large capillary forces upon saturation that prevent removal without collapsing the MOF material. In contrast to the UiO MOFs, both MOF-808 and NU-1000 survived removal of the adsorbents. The PXRD patterns of MOF-808 and NU-1000 after purging in He and heating did not collapse the materials, but did result in some structural changes (Fig. S2).
Apart from changes in the peak intensity, we observed that exposure to DMMP shifts reflections toward lower $2 \theta$ angles, indicating the expansion of the lattice for all MOFs (Figs. S4S7). LeBail fits were performed on 10 - 20 patterns collected during each experiment in order to extract the unit cell parameters. This analysis reveals that, for each MOF, the unit cell expands during the experiment, with the most significant change observed for MOF-808, where the unit cell volume expanded from $44516(6) \AA^{3}$ to $45110(6) \AA^{3}$ (1.33\% increase) after $1 \mathrm{~h}$ (Table S1, Fig. 2). For UiO-67 and NU-1000, the process starts immediately upon exposure and expansion slows or even reverses slightly following the initial 30 minutes of exposure $(1.17 \%$ and $0.76 \%$, respectively). The decreases in UiO-67 volume after $60 \mathrm{~min}$ of DMMP dosing suggest either ongoing reaction (provided reaction products have smaller volume than DMMP) or destruction of the material. Finally, the unit cell of UiO-66 changes almost as much as for MOF-808 (1.30\%), but the process is much slower, and progresses throughout the $11 \mathrm{~h}$ duration of the experiments. The different rates of expansion may be due to the fact that UiO-66 has smaller pores than the other materials and the rate of expansion is limited by slow diffusion.

Beyond structural changes to the MOF, the PXRD data provide insight into the location of adsorbed DMMP and/or products of DMMP decomposition within the MOFs via 
Fourier difference analysis of the empty and DMMP-loaded frameworks. The starting structural model for the MOF frameworks was refined with the Rietveld method from the data acquired from the desolvated samples in He (Figs. S8S10). The electron density maps calculated for UiO-66, MOF808 and NU-1000 from the patterns collected at the end of each experiment are shown in the Figure 1c and Figures S11S12; for UiO-67, the Fourier analysis was not viable (see SI). The results indicate that the highest electron density increase occurs in the periphery of the $\mathrm{Zr}_{6}$ clusters, where adsorption/reaction occurs, as well as in the middle of the pores, as expected when the pores become occupied (Fig. 1).

To complement the in situ PXRD experiments, we measured the PXRD data from the desolvated samples exposed to DMMP in air ex situ in a closed container for $48 \mathrm{~h}$. Collected data show similar changes to those observed from the in situ experiments, with the peak intensity decreasing and peak position shifting towards lower angles (Figs. S13-S16, Table S2). These results suggest that MOFs adsorb DMMP from the air, offering the applicability of these MOFs to reallife conditions.

While the PXRD data revealed key structural changes to the MOFs upon adsorption (and desorption) and that the $\mathrm{Zr}_{6}$ cluster is the main site for DMMP uptake, additional techniques are required to help determine the reaction mechanism. We performed a series of in situ EXAFS experiments on the $\mathrm{Zr} \mathrm{K}$-edge while the MOF samples were exposed to DMMP. For these studies, the desolvated MOFs were exposed to DMMP vapor for up to $11 \mathrm{~h}$ with continuous EXAFS data collection. The resulting time-resolved EXAFS plots reveal that, for all samples, the $\mathrm{Zr}-\mathrm{O}$ and $\mathrm{Zr}-\mathrm{Zr}$ peaks decrease due to increased disorder (Fig. 1b, Fig S17), suggesting that DMMP interacts with $\mathrm{Zr}$ directly. Quantitative analysis fully reproduces the previously reported $\mathrm{Zr}-\mathrm{O}$ and $\mathrm{Zr}$ $\mathrm{Zr}$ distances for a hydroxylated UiO-66 MOF (Table S3). ${ }^{32}$ The other three MOFs studied here have similar distances between $\mathrm{Zr}$ and its nearest $\mathrm{O}$ and $\mathrm{Zr}$ neighbors, thus confirming that all four MOFs were hydroxylated during the interaction with DMMP. Because the positions of the $\mathrm{Zr}-\mathrm{Zr}$ peaks did not change during $\mathrm{He}$ activation and DMMP exposure, we interpret the reduction in the peak intensity with time as caused by the increased disorder in $\mathrm{Zr}-\mathrm{O}$ and $\mathrm{Zr}-\mathrm{Zr}$ distances during adsorption/reaction. The fact that the $\mathrm{Zr}$ environment is affected by DMMP exposure, coupled with the results from the diffraction experiments that indicate DMMP enters MOF pores, provides strong evidence that DMMP interacts directly with $\mathrm{Zr}$.

To evaluate the fate of DMMP within the pores of the four MOFs and characterize reaction products, we performed in situ Diffuse Reflectance Fourier Transform Spectroscopy (DRIFTS). In all four cases, spectra show both bands associated with DMMP adsorption and those belonging to the products of decomposition into methyl methylphosphonate (MMP). The main features arising from DMMP adsorption are the peaks assigned as $v(\mathrm{P}=\mathrm{O})$ located between 1200 and 1300 $\mathrm{cm}^{-1}$. The observed MMP modes include $v_{\mathrm{a}}(\mathrm{OPO})$ at $\sim 1175$ $\mathrm{cm}^{-1}, \rho(\mathrm{OCH} 3)$ at $\sim 1125 \mathrm{~cm}^{-1}, v_{\mathrm{s}}(\mathrm{OPO})$ at $\sim 1075 \mathrm{~cm}^{-1}$ and $v(\mathrm{CO})$ at $\sim 1060 \mathrm{~cm}^{-1}$ (for a detailed description see SI). Differences in structural geometry of MOFs results in different spectral response and the shape of spectra, but in all the cases we can see the result of DMMP decomposition (Figs. S22S26).
The EXAFS and time-dependent DRIFTS data illuminate the reaction mechanism for the DMMP decomposition on $\mathrm{Zr}$ MOFs. This mechanism is also informed by recent computational work on the decomposition of Sarin on the $\mathrm{Cs}_{8} \mathrm{Nb}_{6} \mathrm{O}_{19}$ Lindqvist hexaniobate and $\mathrm{Zr-MOFs}{ }^{33,34}$ The starting point of the reaction is a complex in which DMMP is bound to an undercoordinated $\mathrm{Zr}$ atom of the MOF adjacent to a $\mathrm{Zr}-\mathrm{OH}$ group (Scheme 1). The reaction mechanism consists of two elementary steps: i) nucleophilic addition of the hydroxide ligand to DMMP to generate a pentacoordinated phosphorus intermediate, and ii) decomposition of the pentacoordinated intermediate via elimination of methanol $(\mathrm{MeOH})$, to produce methyl methylphosphonate bound to the $\mathrm{Zr}_{6}$ cores, as shown by the DRIFTS spectra. As noted in the computational study of Sarin decomposition with Zr-MOFs, ${ }^{34}$ elimination of products from intermediate requires a proton transfer to the leaving group. The proton can be transferred from the hydroxide ligand that undergoes nucleophilic addition, or from a $\mu_{3}-\mathrm{OH}$ group in a face of the $\mathrm{Zr}_{6}$ octahedron. In both cases, the structure of the $\mathrm{Zr}_{6}$ octahedron is perturbed by the reaction, thus altering the $\mathrm{Zr}-\mathrm{O}$ and $\mathrm{Zr}-\mathrm{Zr}$ bonding framework and lowering the intensity of EXAFS oscillations.
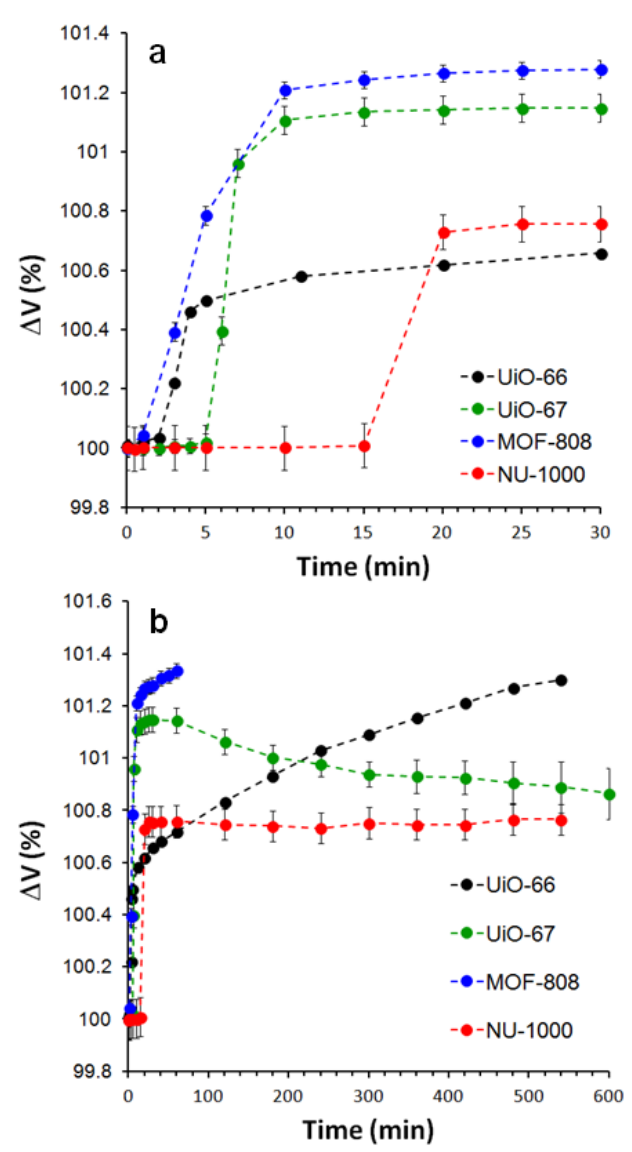

Figure 2. Evolution of UiO-66, UiO-67, MOF-808 and NU1000 unit cell volumes with the dosing of DMMP (a) first 30 minutes of dosing and (b) full experiment.

Initially, both $\mathrm{MeOH}$ and MMPA products are bound to the MOF. MeOH interacts to the MOF via a hydrogen bond, but the MMPA products are strongly bound to the MOF through covalent bonds. In fact, the desorption energy of MMPA 
$(>100 \mathrm{~kJ} / \mathrm{mol})^{34}$ is large enough that the binding of this phosphonic acid to the MOF is irreversible under ambient conditions.

\section{SCHEME 1. Mechanism of DMMP decomposition.}

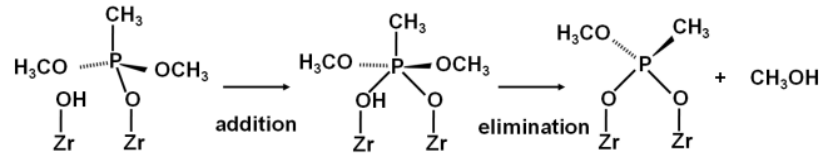

In conclusion, our results show that $\mathrm{Zr}-\mathrm{MOF}$ are attractive andidates for future development of CWA decontamination materials at the gas-surface interface. In all four cases, the Sarin simulant DMMP is adsorbed within the pore space, as evident from in situ PXRD data, and undergoes decomposition to MMP species, as evident from DRIFTS results. Further, we showed that DMMP is actively adsorbed from the air, even in the presence of humidity or other ambient gases, demonstrating that $\mathrm{Zr}_{6}$-based MOFs may serve as effective sorbents for CWAs under ambient conditions. However, our results indicate that exposure of these MOFs to vapor-phase organophosphonates may lead to strongly bound products or MOF collapse that will inhibit the catalytic process that has been extensively reported in solution. ${ }^{10}$ Our studies highlight critical design criteria for the development of future vaporous CWA decontamination materials and catalysts. Most importantly, effective materials will require facile diffusion to active sites while avoiding strong binding of phosphonic acid products to the catalyst. In addition, the determination of reaction products reported in this work will stimulate development of post-exposure treatments to regenerate the MOF catalysts.

\section{ASSOCIATED CONTENT}

This material is available free of charge via the Internet at http://pubs.acs.org. Supporting Information File containing experimental description, supplementary figures S1-S26 and supplementary tables S1-S5 (PDF)

\section{AUTHOR INFORMATION}

\section{Corresponding Author}

* anatoly.frenkel@ stonybrook.edu

\section{Author Contributions}

The manuscript was written through contributions of all authors.

\section{ACKNOWLEDGMENT}

This work is supported by the U. S. Army Research Laboratory and the U. S. Army Research Office under grant number W911NF-15-2-0107. The authors thank the Defense Threat Reduction Agency for support under program BB11PHM156. Use of Advanced Photon Source, Stanford Synchrotron Radiation Lightsource, and National Synchrotron Light Source II was supported by the U.S. Department of Energy under Contracts No. DE-AC02-06CH11357, DE-AC02-76SF00515 and DESC0012704, respectively. In situ operations at the BL2-2 beamline at SLAC were made possible by the U. S. Department of Energy grant No. DE-SC0012335. AIF and QW thank Prof. C. Lamberti for valuable discussions. The authors are grateful to Prof. J. T. Hupp and Prof. O. K. Farha for generously providing sample of NU-1000.

\section{REFERENCES}

(1) Yang, Y. C.; Baker, J. A.; Ward, J. R. Chem. Rev. 1992, 92, 1729.

(2) Smith, B. M. Chem. Soc. Rev. 2008, 37, 470.

(3) Wagner, G. W.; Peterson, G. W.; Mahle, J. J. In. Eng. Chem. Res. 2012, $51,3598$.

(4) Bandosz, T. J.; Laskoski, M.; Mahle, J.; Mogilevsky, G.; Peterson, G W.; Rossin, J. A.; Wagner, G. W. J. Phys. Chem. C 2012, 116, 11606.

(5) Kinnan, M. K.; Creasy, W. R.; Fullmer, L. B.; Schreuder-Gibson, H. L.; Nyman, M. Eur. J. Inorg. Chem. 2014, 2014, 2361.

(6) Guo, W.; Lv, H.; Sullivan, K. P.; Gordon, W. O.; Balboa, A.; Wagner, G. W.; Musaev, D. G.; Bacsa, J.; Hill, C. L. Angew. Chem. Int. Ed. 2016, 55, 7403-7407.

(7) López-Maya, E.; Montoro, C.; Rodríguez-Albelo, L. M.; Aznar Cervantes, S. D.; Lozano-Pérez, A. A.; Cenís, J. L.; Barea, E.; Navarro, J. A. Angew. Chem. Int. Ed. 2015, 54, 6790 .

(8) Mondal, S. S.; Holdt, H. J. Angew. Chem. Int. Ed. 2016, 55, 42.

(9) Mondloch, J. E.; Katz, M. J.; Isley III, W. C.; Ghosh, P.; Liao, P.; Bury, W.; Wagner, G. W.; Hall, M. G.; DeCoste, J. B.; Peterson, G. W. Nat. Mater. 2015, 14, 512

(10) Moon, S. Y.; Liu, Y.; Hupp, J. T.; Farha, O. K. Angew. Chem. Int. Ed. 2015, 54, 6795

(11)Zhou, H.-C.; Long, J. R.; Yaghi, O. M. Chem. Rev. 2012, 112, 673.

(12) Getman, R. B.; Bae, Y.-S.; Wilmer, C. E.; Snurr, R. Q. Chem. Rev. 2011, 112, 703 .

(13) Suh, M. P.; Park, H. J.; Prasad, T. K.; Lim, D.-W. Chem. Rev. 2011, 112,782 .

(14) Sumida, K.; Rogow, D. L.; Mason, J. A.; McDonald, T. M.; Bloch, E. D.; Herm, Z. R.; Bae, T.-H.; Long, J. R. Chem. Rev. 2011, 112, 724.

(15) Plonka, A. M.; Chen, X.; Wang, H.; Krishna, R.; Dong, X.; Banerjee, D.; Woerner, W. R.; Han, Y.; Li, J.; Parise, J. B. Chem. Mater. 2016, 28 , 1636.

(16) Banerjee, D.; Simon, C. M.; Plonka, A. M.; Motkuri, R. K.; Liu, J.; Chen, X.; Smit, B.; Parise, J. B.; Haranczyk, M.; Thallapally, P. K. Nat. Commun. 2016, 7 .

(17) DeCoste, J. B.; Peterson, G. W. Chem. Rev. 2014, 114, 5695.

(18) Furukawa, H.; Cordova, K. E.; O'Keeffe, M.; Yaghi, O. M. Science 2013, 341, 1230444

(19) Lee, J.; Farha, O. K.; Roberts, J.; Scheidt, K. A.; Nguyen, S. T.; Hupp, J. T. Chem. Soc. Rev. 2009, 38, 1450.

(20)Stassen, I.; Bueken, B.; Reinsch, H.; Oudenhoven, J.; Wouters, D.; Hajek, J.; Van Speybroeck, V.; Stock, N.; Vereecken, P.; Van Schaijk, R. Chem. Sci. 2016, 7, 5827-5832.

(21)Bai, Y.; Dou, Y.; Xie, L.-H.; Rutledge, W.; Li, J.-R.; Zhou, H.-C. Chem. Soc. Rev. 2016, 45, 2327.

(22)Mondloch, J. E.; Katz, M. J.; Planas, N.; Semrouni, D.; Gagliardi, L.; Hupp, J. T.; Farha, O. K. Chem. Commun. 2014, 50, 8944.

(23)Shearer, G. C.; Chavan, S. M.; Ethiraj, J.; Vitillo, J. G.; Svelle, S.; Olsbye, U.; Lamberti, C.; Bordiga, S.; Lillerud, K. P. Chem. Mater. 2014, 26, 4068-4071.

(24)Moon, S.-Y.; Wagner, G. W.; Mondloch, J. E.; Peterson, G. W.; DeCoste, J. B.; Hupp, J. T.; Farha, O. K. Inorg. Chem. 2015, 54, 10829. (25)Peterson, G. W.; Moon, S.-Y.; Wagner, G. W.; Hall, M. G.; DeCoste, J. B.; Hupp, J. T.; Farha, O. K. Inorg. Chem. 2015, 54, 9684.

(26)Bordiga, S.; Bonino, F.; Lillerud, K. P.; Lamberti, C. Chem. Soc. Rev. 2010, 39, 4885 .

(27)Singh, J.; Lamberti, C.; van Bokhoven, J. A. Chem. Soc. Rev. 2010, 39,4754 .

(28)Chavan, S.; Vitillo, J. G.; Gianolio, D.; Zavorotynska, O.; Civalleri, B.; Jakobsen, S.; Nilsen, M. H.; Valenzano, L.; Lamberti, C.; Lillerud, K. P. Phys. Chem. Chem. Phys. 2012, 14, 1614.

(29)Mondloch, J. E.; Bury, W.; Fairen-Jimenez, D.; Kwon, S.; DeMarco, E. J.; Weston, M. H.; Sarjeant, A. A.; Nguyen, S. T.; Stair, P. C.; Snurr, R. Q. J. Am. Chem. Soc. 2013, 135, 10294.

(30)Furukawa, H.; Gándara, F.; Zhang, Y.-B.; Jiang, J.; Queen, W. L.; Hudson, M. R.; Yaghi, O. M. J. Am. Chem. Soc. 2014, 136, 4369. (31)Young, D. S. "The Rietveld method", Oxford University Press, Oxford, United Kingdom, 1993.

(32)Valenzano, L.; Civalleri, B.; Chavan, S.; Bordiga, S.; Nilsen, M. H.; Jakobsen, S.; Lillerud, K. P.; Lamberti, C. Chem. Mater. 2011, 23, 1700 (33)Chapleski, R. C.; Musaev, D. G.; Hill, C. L.; Troya, D. J. Phys. Chem. C 2016, 120, 16822

(34)Troya, D. J. Phys. Chem. C 2016, DOI: 10.1021/acs.jpcc.6b10530 


\section{TOC GRAPHICS}

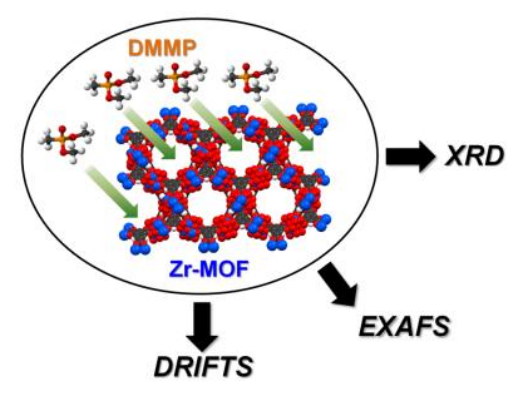

